\title{
Prediction of Internet addiction based on emotion seeking and Identity styles in students
}

\author{
Akram Gheibi ${ }^{1}$, Heidar Ali Zarei ${ }^{2}$ \\ 1- M.A in clinical psychology, Department of Humanities, Urmai Branch, Islamic Azad University, Urmia, Iran. \\ ORCID: 0000-0001-8116-6528 \\ 2-Corresponding Author: Assistant of educational psychology, Department of Humanities, khoy Branch, Islamic \\ Azad University, khoy, Iran. ORCID: 0000-0003-4572-2325Ｅ-mail: alizarei@iaukhou.ac.ir
}

Received: 18/07/2018

Accepted: 02/10/2018

\begin{abstract}
Introduction: The excessive and incorrect use of the Internet and its related technologies by adolescents is a one of common and important problem in our community.

Aim: The aim of the present study was to predict the Internet addiction based on identity styles and excitement-seeking in students.

Method: the participants in this study were 200 students $(n=101$ boy, 99 girl $)$ who selected with available sampling procedure. The research method was descriptive - correlative.

Results: In general, Multivariate regression analysis showed that it can be significantly predicted Internet addiction based on the elements of sensation seeking. Also The results showed that informational identity styles and commitment have significant negative correlations with Internet addiction and there is a significant positive relationship between normative style and diffuse / avoidant style with Internet addiction. Internet addiction Based on these styles can be significantly predicted.
\end{abstract}

Conclusion: In the prevention and treatment of Internet addiction is essential given the role of sensation seeking and identity styles.

Keywords: Addiction to the Internet, the excitement, identity styles

How to cite this article : Gheibi A, Zarei H A. Prediction of Internet addiction based on emotion seeking and identity styles in students. Shenakht Journal of Psychology and Psychiatry. 2018; 5 (3): 53-65 .URL :http://shenakht.muk.ac.ir/article-1-408-fa.pdf

Copyright $\odot 2018$ the Author (s). Published by Kurdistan University of Medical Sciences. This is an open access article distributed under the terms of the Creative Commons Attribution-Non Commercial License 4.0 (CCBY-NC), where it is permissible to download, share, remix, transform, and buildup the work provided it is properly cited. The work cannot be used commercially without permission from the journal. 


\section{ييشبينى اعتياد به اينترنت بر اساس هيجان خواهى و سبكهاى هويت در دانش آموزان}

\section{اكرم غيبى'، حيدر على زارعى}

ا. كارشناس ارشد روانشناسى بالينى، گروه روان شناسى، واحد اروميه، دانشكاه آزاد اسلامى، اروميه، ايران

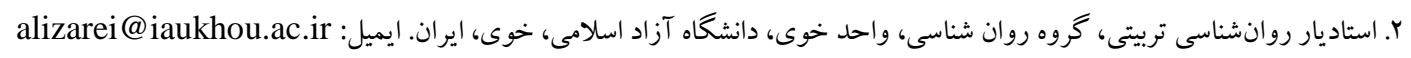

مقدمه: استفاده بيش از حد و نادرست از ايترنت و فناورى هاى مرتبط با آن توسط نوجوانان، يكى از مشكلات رايج و مهم

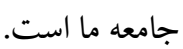
هدف: يُزوهش حاضر بهمنظور يُشبينى اعتياد به اينترنت بر اساس هيجان خواهى و سبك هاى هويت در دانش آموزان انجام شد.

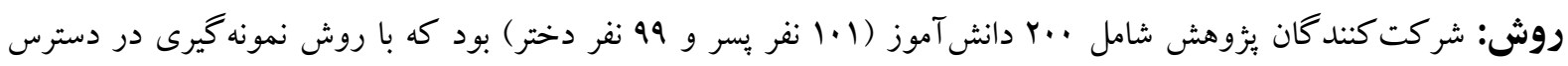

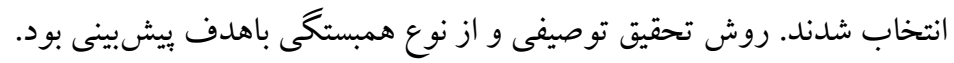
يافته ها: نتايج ركرسيون جند متغيرى نشان داد مىتوان بر اساس مؤلفهاى هيجان خواهى، ميزان اعتياد به اينترنت را بهصورت

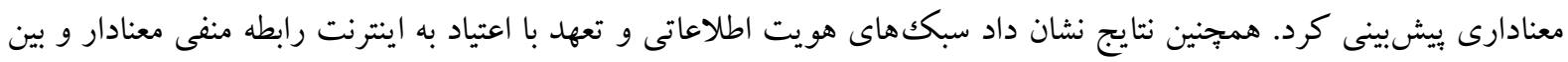

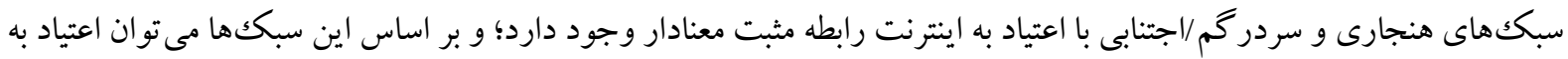
اينترنت را بهصورت معنادارى بيشبينى كرد. نتيجه كيرى: در ييشگيرى و درمان اعتياد به اينترنت توجه به نقش هيجان خواهى و سبك هاى هويت ضرورى است. كليدوازهها: اعتياد به اينترنت، سبككهاى هويت، هيجان خواهى 
كو و وونه (Y.|F) در يكك فراتحليل در خصوص

مقلهمه

مطالعات انجام شده در زمينه اعتياد به اينترنت به اين نتيجه دست يافتند كه اندازه اثر عو امل درون فردى در اعتياد به اينترنت بيشتر از عوامل بين فردى است. هيجان خواهى و تنظيم هيجانات از جمله عوامل درون فردى بود كه در وابستخى به اينترنت نقش مؤثرى داشت. در در همين راستا، مظاهرى نجات فرد و حسينى ثابت (Y.IV)

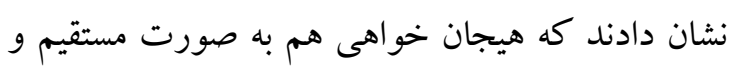
هم به صورت غيرمستقيم و از طريق سبكهاى

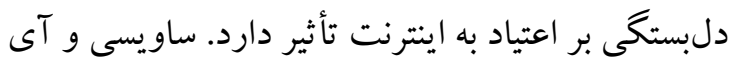

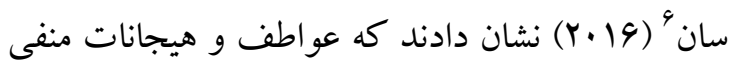
يبش بينى كننده اعتياد به اينترنت در جوانان هستند. سيز

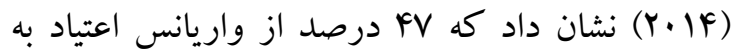
اينترنت از طريق هيجان خواهى و جنسيت تبيين مى -

جستجو در اينترنت و شبكههاى مجازى يا بيشتر فعاليتهاى آنلاين، بهطور گستردهاى بهعنوان تجربه فنّاورى برتر ارزيابى مىشود. از اين رو مىتواند بهنوان نوعى هيجان خواهى مطرح شود. محققان هيجان خواهى را بهصورت صفتى كه ويز گیى آن جستجوى هيجانها و تجربه متنوع، تازه بيجيجيده و شديد

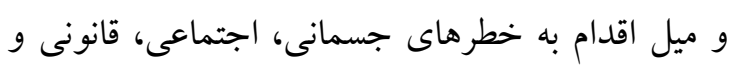
مالى به خاطر خود تجربهها است، تعريف مى كند.

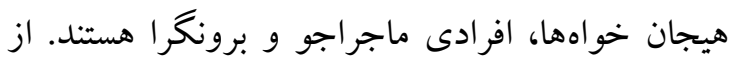
تكرار و يكنواختى خسته، كسل و بـى حوصله و بى قرار مىشوند و در جستجوى تجارت جديد، متنوع و هيجانانگيزند (حيدرى و همكاران، بوس ا). از نظر زاكرمن رفتار هيجان خواهى نوعى نياز به

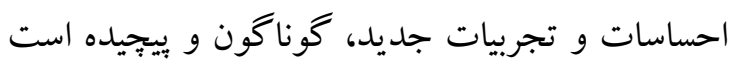
و شخص داراى جنين رفتارى حاضر است براى به

\footnotetext{
${ }^{5}$-Koo \& Kwon

6 - Savcı \& Aysan

7 -Siyez
}

\footnotetext{
${ }^{1}$-Kuss, Griffiths \& Binder

${ }^{2}$-kuss

${ }^{3}$-Lehen Buoer

4- Kim, NamKoong, Ku, \& Kim
}

در سالهاى اخير ايتترنت به مهمترين ابزار علمى و

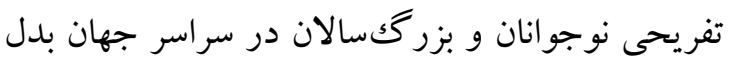

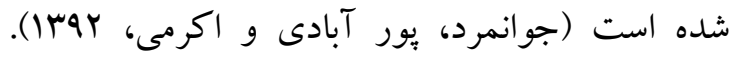

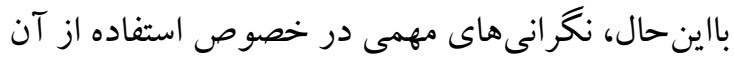

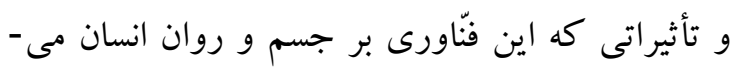
كذارد، وجود دارد. كاربران در بيى استفاده روزافزون

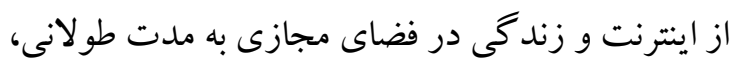

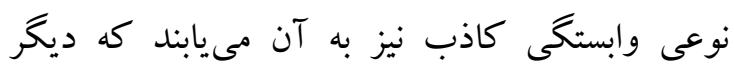

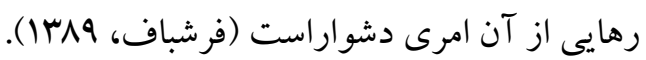

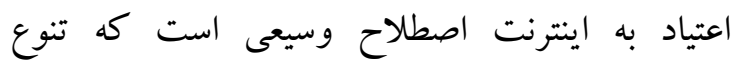

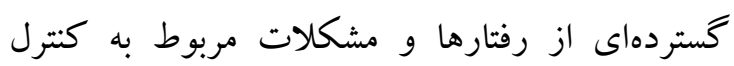

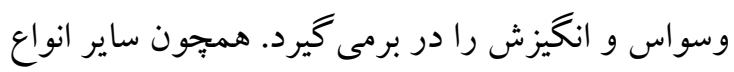

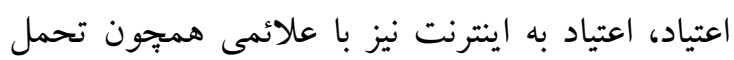

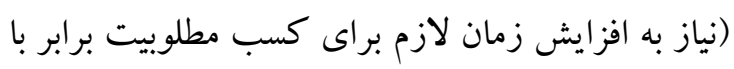

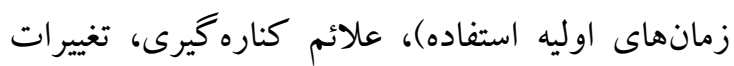

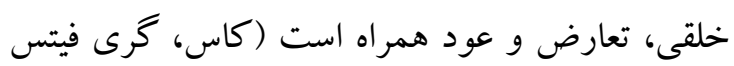

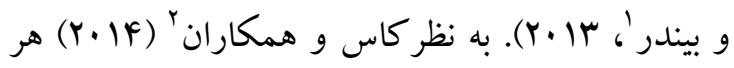

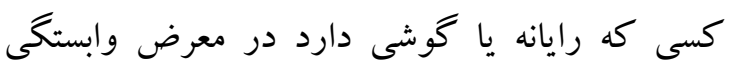
است اما افرادى كه خجالتى، افسرده، تنها و بى دوصو دابله هستند، بيشتر در معرض خطر قرار دارند. وابستخى به فناورى بهطور عملياتى مىتواند در درارند

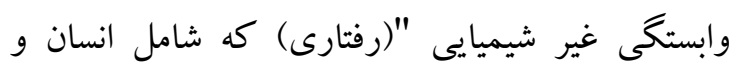

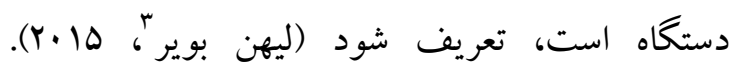

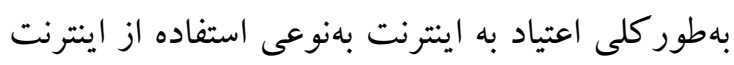

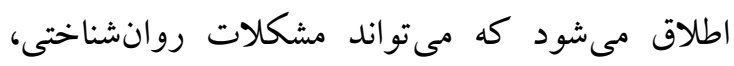

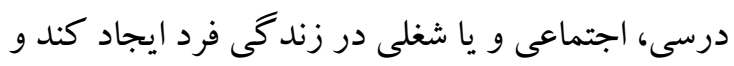

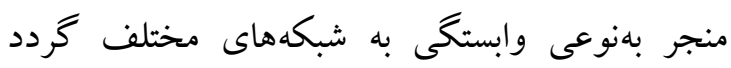

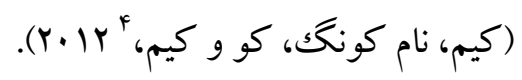


تأخيرهاى طولانى انجام مىدهند، منبع كنترل بيرونى

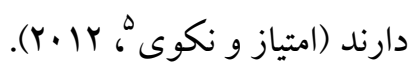

شواهد بيزوهشى نشان مى دهد كه اعتياد به اينترنت با بان سبك هويت اطلاعاتى و هنجارى در دانشجويان رابطه منفى و با سبك هويت مغشوش -اجتنابى رابطه مثبت دارد (رحمتى و كرامتى، هوبا!؛ سلطانى، فولادوند و ونى فتحى آشتيانى،

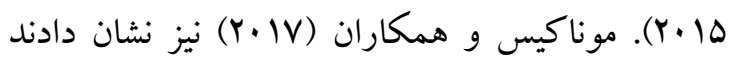
كه سبك هاى هويت اطلاعاتى و مغشوش-اجتنابى

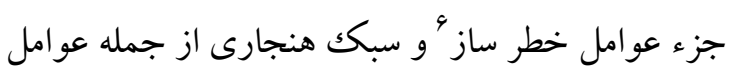
عوامل محافظت كننده در اعتياد به اينترنت محسوب مىشوند. شيرين كام و همكاران (19 (Y) نشان دادند كه اعتياد به اينترنت با خودكنترلى رابطه منفى و و همران

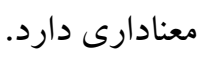

با توجه به مبانى نظرى كه در بالا اشاره شد و همجينين سوابق بثزوهشى راجع به متغيرها كه نشان مىدهند

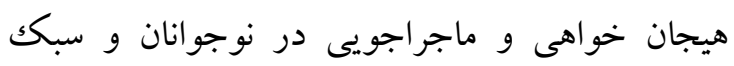

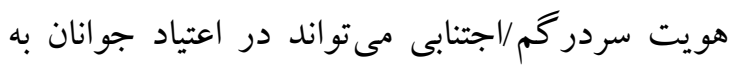
اينترنت نقش داشته باشد. مرور بيشينه تحقيق نشان مى دهد كه رابطه بين اين سه متغير به شكل همزمان مطالعه نشده و تحقيقات انجام شده بيشتر در مورد دانشجويان بوده است؛ و از آنجايى كه اين موضوع تازه و مشكل به روز و مهم خانوادهها و جامعه هست و بز بزوهش جندانى درباره آن در مورد دانش آموزان انجام نكر فته است، لذا تحقيق حاضر بهمنظور بيشبينى اعتياد به

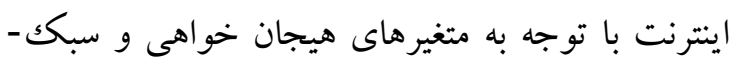
هاى هويت انجام شده است.
دست آوردن اين گونه تجربيات به اعمال مخاطرهآميز اجتماعى يا فيزيكى اقدام كند (نقل از ذوالفقارى زعفرانى و كلانترى، هوب1). هيجان خواهى مى تواند

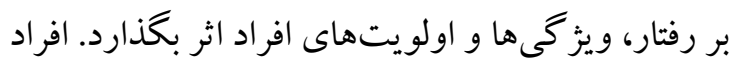
داراى هيجان جويى به فعاليتهايى مىبردازند كه با تحركى و انخيزش زيادى همراه است (روبرتى'، (Y... F

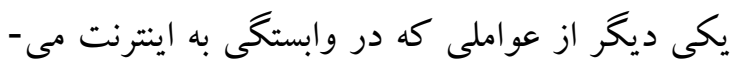
تواند مؤثر باشد، سبك هو هويتى شخص است.

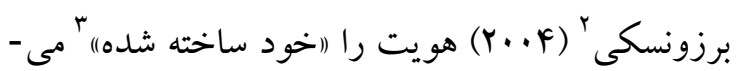

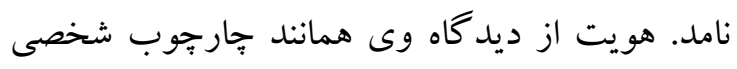
محسوب مىشود كه بهمنزله منبعى براى تفسير تجارب،

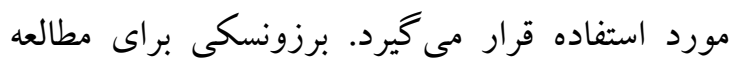

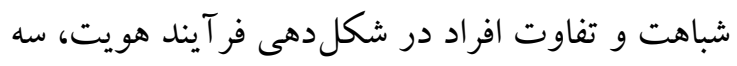
سبك هويت اطلاعاتى، سبك هويت هنجارى، سبك هويت سردر گم/ اجتنابى را شناسايى كرده است: افر اد با سبك هويت اطلاعاتى، داراى راهبردهاى مسئله

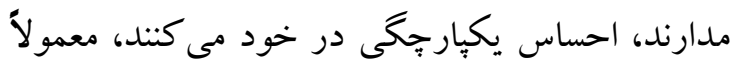
قضاوتها را به تعويق مىاندازند، اهداف شغلى و تحصيلى روشن و انتظار عملكرد تحصيلى بالا دارند و

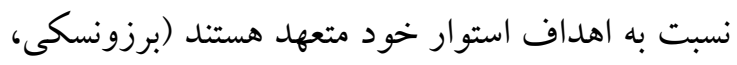
(Y..F ملاككهاى ديخران را درونى مى كنند، احتياج به هونه سازماندهى بيرونى دارند، تمايل به اطلاعاتى دارند كه مطابق بارزشهايشان است. ذهنى بسته دارند

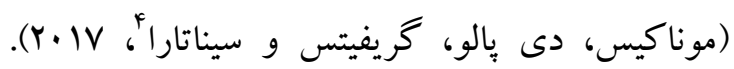

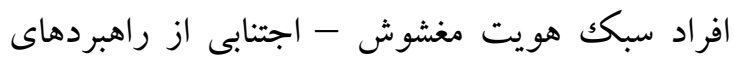

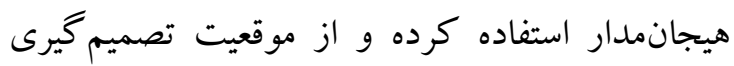

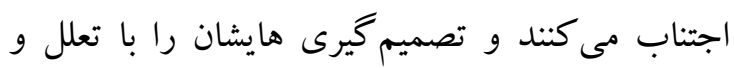

\footnotetext{
-Roberti

2 - Berzonsky

3 - Self-Constructed

4 - Monacis, de Palo, Griffiths \& Sinatra
} 
هويت برزونسكى و ج: اعتياد به اينترنت يانگك استفاده

از آنجا كه هدف يثزوهش حاضر بيشبينى اعتياد به

يرسشنامه هيجان خواهى زاكومن: مقياس هيجان اينترنت بر اساس هيجان خواهى و سبكهاى هويت

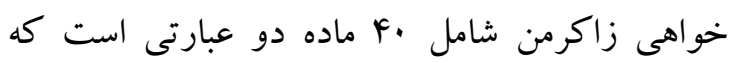
است، لذا طرح بثزوهش توصيفى و از نوع همبستخى با آزمودنى ملزم است يكى از دو جزء هر ماده را حتماً

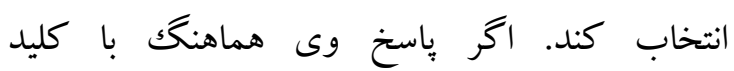
هدف بيشبينى است. تحقيق حاضر در موقعيت طبيعى

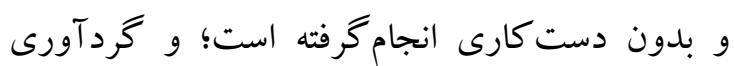
نمره كذارى باشد در ازاى هر پِاسخ هماهنگك با كليد

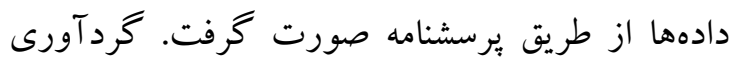

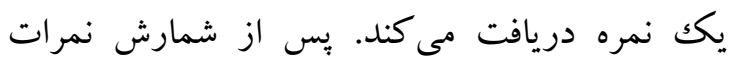

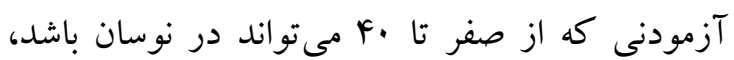
نمره هيجان خواهى فرد مشخص مى شود. آزمون حاضر

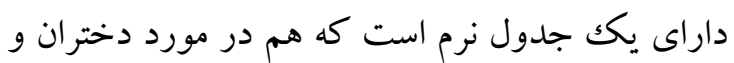
هم پِران يكسان است. يُايايى برسشنامه با استفاده از

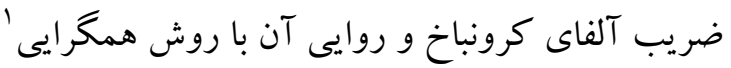
در تحقيقات سلمانى، حسنى و آريانا كيا (سهبا) و

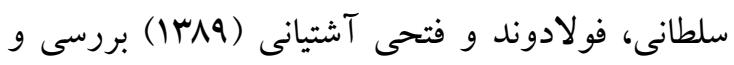
تائيد شده است. برسشنامه سبك هويت برزونسكى: برسشنامه سبك

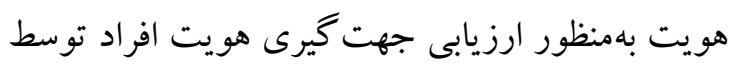
برزونسكى در سال 1919 ساخته شد و در سال بهو 1999 مورد تجديد قرار كرفت. اين آزمون يكك ابزار خود

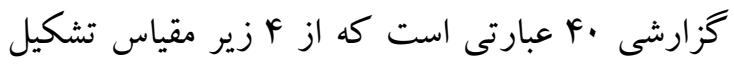
شده است كه ب تا از آنها شامل سبككهاى هويت و و جهارمين زير مقياس مربوط به تعهد است. آزمودنى بايد در يكك مقياس ليكرت ه درجهاى (1=اصلاً شبيه

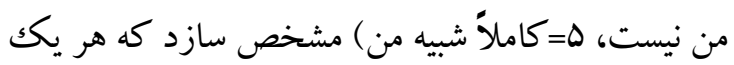

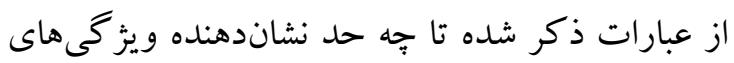

$$
\text { شخصيتى وى است. }
$$

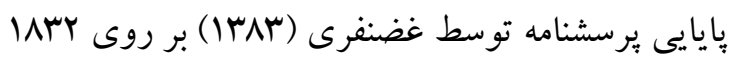
دانش آموز دبيرستانى اجرا و هنجاريابى شده است؛ كه برسئ

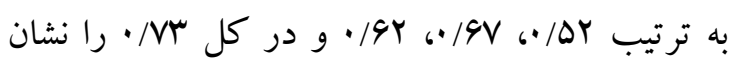
ابزار

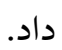
دادهها از طريق برسشنامه صورت گرفت. جامعه آمارى يثزوهش حاضر شامل كليه دانش آموزان دختر و بسر پايه سوم دوره دوم متوسطه شهر خوى در سال تحصيلى

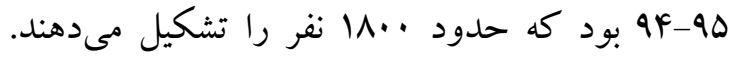

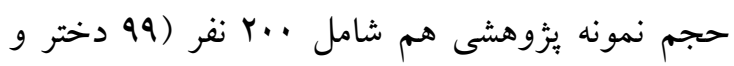
1. (بسر) از جامعه آمارى تحقيق است كه با استفاده از جدول مور گان و با روش نمونه گيرى تصادفى در دسترس انتخاب شده است. دامنه سنى اعضاى نمونه

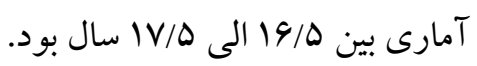
مهم ترين ملاكك ورود به نمونه تحقيق، دانش آموز بايه سوم دوره دوم متوسطه بودن و علاقه به تكميل

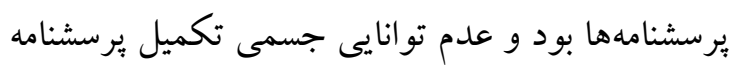
به دليل معلوليت بينايى و عدم رضايت از شركت در مطالعه ازجمله ملاككهاى خروج از مطالعه بود. قبل از اجراى برسشنامهها همه موارد اخلاقى از جمله آكاه كردن افراد از اهداف تحقيق، محرمانه بودن نتايج، داوطلبانه بودن شركت در تحقيق، داشتن حق انصراف در هر مرحله تحقيق و عدم آسيب روانى و جسمى به شركت كنند كان به همه اعضاى نمونه تحقيق اطلاع ورعين

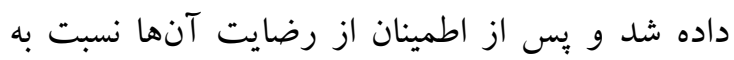
تكميل برسشنامه ها اقدام شد. براى جمع آورى دادههاى لازم از سه يرسشنامه

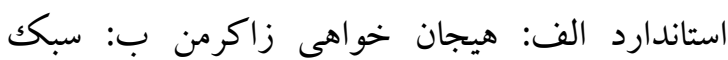




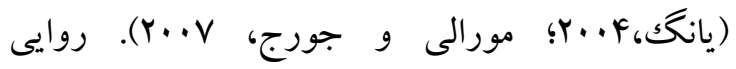

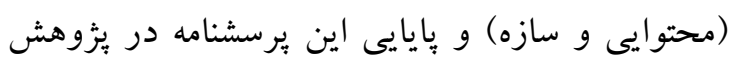

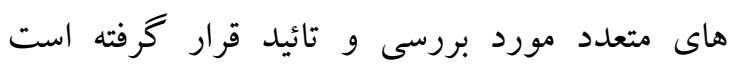

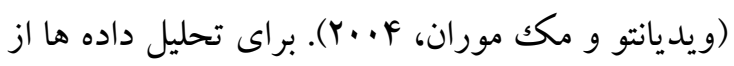
روش هاى آمار توصيفى (شاخص هاى كرايش

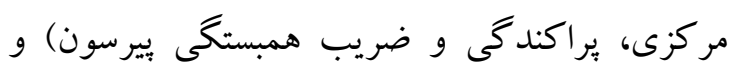

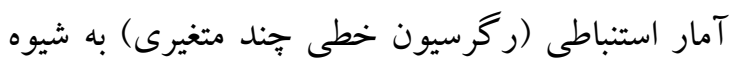

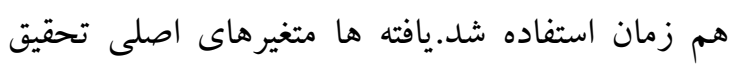
حاضر شامل هيجان خواهى و سبك هاى هويت و اعتياد

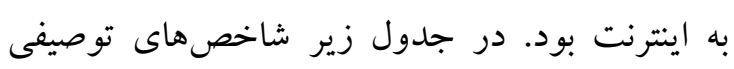
متغيرهاى اصلى بثزوهش و مؤلفه باى آنها ارائه شده

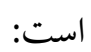

روايى همخراى برسشنامه از طريق ارزيابى همبستخى آن با مقياس وضعيت هويت بنيون و آدامز (1919) تائيد شده است و در بثزوهش غضنفرى بهمنظور ارزيابى يرسشنامه سبك هويت، اين آزمون و مقياس سلامت

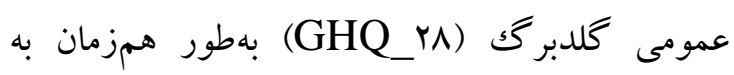
آزمودنىها داده شد و يافتهها بيان خر روايى برسشنامه بودند. يوسشنامه اعتياد به ايتترنت يانتك: برسشنامه يانغك در سال 1991 توسط كيمبرلى يانگك ساخته شد و يكى از معتبرترين برسشنامه ها در زمينه اعتياد اينترنتى

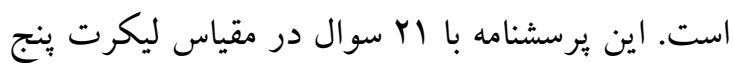
درجه اى (از صفر تا F) است. بدين ترتيب دامنه نمره

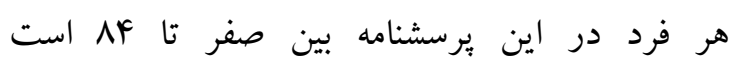

جدول 1: شاخصهاى توصيفى متغيرهاى اصلى ثزوهش ( • (N=r)

\begin{tabular}{|c|c|}
\hline ميانكين (انحراف معيار) & سبك ياد \\
\hline$(11 / \Gamma \varphi) \Gamma V / r \Delta$ & سبك اطلاعاتى \\
\hline$\left.(V / .9) r Y / T^{\prime}\right)$ & سبك هنجارى \\
\hline$(1 \cdot / \wedge q) Y V / q V$ & سبك سردر كم/|جتنابى \\
\hline$(F / A I) r \cdot / \Delta F$ & تعهد \\
\hline$(\Delta / Y Y) Y M / / F$ & هيجان خواهى \\
\hline$(\mid \& / \wedge q) r \cdot / N q$ & اعتياد به اينترنت \\
\hline
\end{tabular}

دارد. در ماتريس زير ضرايب همبستكى انواع مؤلفه هاى هيجان خواهى با متغير اعتياد به اينترنت ارائه

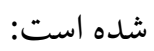

براساس دادههاى جدول فوق از بين سبكهاى هويت،

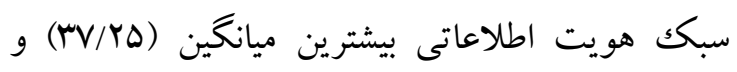

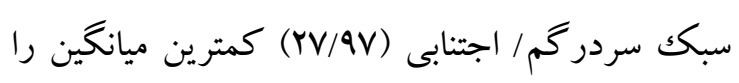

جدول ז: رابطه بين مؤلفه هاى هيجان خواهى و اعتياد به اينترنت

\begin{tabular}{|c|c|c|c|c|c|}
\hline اعتياد به اينترنت & فقدان بازدارى & ملال يذيرى & تجربه يذيرى & ماجر اجويى & مؤلفه هيجان خواهى \\
\hline & & & & 1 & ماجراجويى \\
\hline & & & 1 & "rri. & تجربه هذيرى \\
\hline & & 1 & rVo. & ror. & ملال بذيرى \\
\hline & 1 & rvi. & rat. & r9A. & فقدان بازدارى \\
\hline 1 & rrI. & rAl. & Frl. & pir. & اعتياد به ايتترنت \\
\hline
\end{tabular}

همان گونه كه در جدول فوق (شماره Y) مشاهده مى -

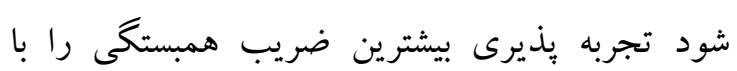


اعتياد به اينترنت دارد. در ماتريس زير (جدول شماره اعتياد به اينترنت ارائه شده است: ب) ضرايب همبستكى انواع سبك هاى هويت با متغير جدول rا: رابطه بين سبككهاى هويت و اعتياد به اينترنت

\begin{tabular}{|c|c|c|c|c|c|}
\hline اعتياد به اينترنت & تعهد & سردر گم/اجتنابى & هنجارى & اطلاعاتى & سبك هويت \\
\hline & & & & 1 & اطلاعاتى \\
\hline & & & 1 & FFF-. & هنجارى \\
\hline & & 1 & r^я. & rgV-. & سردر مم/اجتنابى \\
\hline & 1 & "rlq-. & squ-. & Fil. & تعهد \\
\hline 1 & MFF-. & fro. & $\Delta G F$. & MVG-. & اعتياد به اينترنت \\
\hline
\end{tabular}

آزمون، مفروضههاى رگرسيون جِندمتغيرى از قبيل حجم نمونه مناسب( (N=r. (N)، عدم همخطى جند كانه (شاخصهاى تحمل و VIF)، استقلال باقىماندهها (آزمون دوربين -واتسون) و دادههاى برت بررسى و يس از تائيد وجود مفروضهها به انجام آزمون اقدام شد. در جدول زير خلاصه مدل رگرسيون ارائه شده است:
بر طبق دادههاى جدول فوق همه سبكهاى هويت با اعتياد به اينترنت رابطه معنادارى در سطح 1 • • دارند. فرضيه اول: اعتياد به اينترنت را مىتوان بر اساس متغير هيجان خواهى دانش آموزان بيشبينى كرد. اين فرضيه با استفاده از روش رگرسيون جندمتغيرى با روش همزمان مورد آزمون قرار گرفت و نتايج آن در جداول زير قرار داده شده است. البته قبل از انجام

جدول †: خلاصه تحليل ركرسيون براى بيشبينى اعتياد به اينترنت بر اساس مؤلفههاى هيجان خواهى

\begin{tabular}{|c|c|c|c|c|c|}
\hline مقدار آزمون(19ه)، & آزمون دوربين - واتسون & مجذور Rعديل شده & Rجذور & $\mathbf{R}$ & مدل \\
\hline$r \cdot 19 \Lambda$ & $1 / \Delta r$ & . TAN &.$/ r 91$ &.$/ D \& 4$ & 1 \\
\hline
\end{tabular}

يسماندهاى مدل را نشان ميدهد. مقدار اين آزمون از صفر تا F است مقادير نزديك به ب نشاندهنده عدم وجود همبستخى بين باقى ماندها است. مقدار آزمون

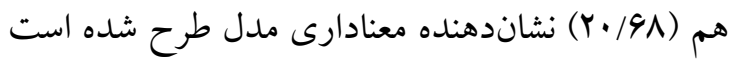

$$
(\mathrm{p}<\cdot 1 \cdot 1)
$$

در جدول زير، ضرايب غيراستاندارد، استاندارد (م)، معنادارى ضرايب و شاخصهاى نشاندهنده همخطى جند گُانه ارائه شده است.
طبق جدول فوق ضريب همبستكى جند گانه مدل برابر

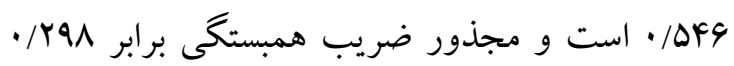
است. اين بدان معنى است كه حدود .ب درصد از واريانس اعتياد به اينترنت بهوسيله متغيرهاى موجود در مدل ركرسيون قابل تبيين است. مقدار آزمون دوربين واتسون نيز برابر اله / است و نشان مىدهد كه مفروضه استقلال باقىماندها در دادهها برقرار است. آزمون دوربين -واتسون همبستخى بين باقىماندهها يا

جدول ه: ضرايب استاندارد و غيراستاندارد ركرسيون به شيوه همزمان و آزمون معنادارى آنها

\begin{tabular}{|c|c|c|c|c|c|c|c|}
\hline \multicolumn{2}{|c|}{ شاخص هم خطى } & \multicolumn{2}{|c|}{ معنادارى ضرايب } & \multicolumn{3}{|c|}{ ضرايب ركرسيون } & \\
\hline Vif & تحمل & سطح & مقدار t & استانداردم & خطاى & غير استاندارد & غير ييشبين \\
\hline
\end{tabular}




\begin{tabular}{|c|c|c|c|c|c|c|c|}
\hline & & معنادارى & & & انحراف & & \\
\hline & & $\Delta \vee \Lambda$. & $\Delta \Delta V$. & & NFI.r & IrA.r & مقدار ثابت C \\
\hline rIr.I & NYF. & $\cdots$ & qFQ.r & rq1. & $\Delta ו \Lambda$. & .kr.r & ماجر اجويى \\
\hline r91.1 & WF. & $\cdots$ & IST.F & rAF. & $\Delta M F$. & MYF.Y & تجربه هذيرى \\
\hline rrv. I & VDF. & $\cdots 9$ & VAT.Y & 191. & $\Delta Y F$. & FFV.I & ملال يذيرى \\
\hline rov. I & va८. & vra. & . &. rY-. & sma. & rir-. & فقدان بازدارى \\
\hline
\end{tabular}

نشان دهنده هم خطى جند

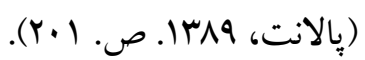

فرضيه دوم: اعتياد به اينترنت را مىتوان بر اساس سبككهاى هويت در دانش آموزان بيشبينى كرد. براى آزمون اين فرضيه از رگرسيون خطى جند كانه به روش همزمان استفاده شد. البته قبل از انجام آزمون، مفروضههاى آن در دادهها بررسى شد و يس از تائيد وجود مفروضهها، آزمون مذكور جهت آزمون فرضيه مورد استفاده قرار كرفت. در جدول زير خلاصه مدل رگرسيون ارائه شده است:
همان كونه كه در جدول فوق ملاحظه مى شود ضرايب ركرسيون ماجراجويى، تجربه يذيرى و ملال يذيرى در سطح 1+ • معنادار است يعنى اين متغيرها به صورت معنادارى مى توانند متغير اعتياد به اينترنت را بيش بينى ليش كند؛ اما ضريب ركرسيون فقدان بازدارى از نظر آمارى معنادار نيست (Sig=>/VMq). مقادير شاخص هاى تحمل و VIF نيز در دامنه مطلوب قرار دارند و اين نشان دهنده اين است كه هم خطى جند گانه بين متغيرهاى ييش بين وجود ندارد. اكر مقدار شاخص تحمل كمتر از // · باشد بيان كر وجود هم

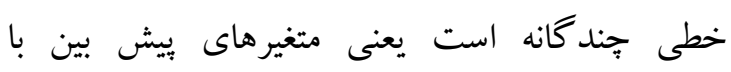
همديگر همبستگى بالايى دارند. همجِنين مقادير بالاى

جدول \&: خلاصه تحليل ركرسيون براى بيشبينى اعتياد به اينترنت بر اساس سبككهاى هويت

\begin{tabular}{|c|c|c|c|c|c|}
\hline 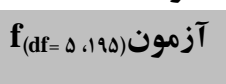 & آزمون دوربين - واتسون & مجذور R تعديل شده & Rجذور & $\mathbf{R}$ & مدل \\
\hline $19 / 49$ & $1 / N r$ & . &.$/ T \Delta$ & $\cdot / \Delta \cdot$ & 1 \\
\hline
\end{tabular}

بين يُامدهاى مدل رگرسيونى همبستگى وجود ندارد و مفروضه استقلال يس ماندهها تائيد مىشود. براى تعيين معنادارى مدل از آزمون تحليل واريانس يككسويه (آنوا) استفاده شد. نتايج حاصل از آزمون مذكور نشاندهنده معنادارى مدل ركرسيونى مفروض بود ( ( ) جدول زير ضرايب رگرسيون شامل ايب غير استاندارد و استاندارد (بتا)، معنادارى ضرايب با استفاده از آزمون t و در نهايت شاخص هم خطى شامل شاخص تحمل و شاخص VIF ارائه شده است:
بر اساس جدول فوق مقدار ضريب همبستگى جند كانه بين سبككهاى هويت و اعتياد به اينترنت برابر ه/ •++

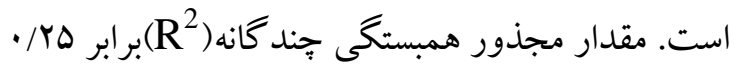
است و نشان مىدهد كه ها درصد از واريانس اعتياد به

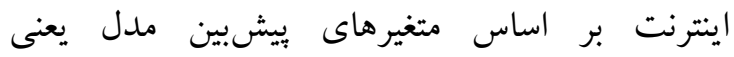
سبككهاى جهار كانه هويت قابل تبيين است. مقدار آزمون دوربين - كواتسون نيز برابر سلاست است. در اين آزمون مقادير نزديكك به Y نشاندهنده عدم وجود همبستگ بين باقىماندهها است. لذا مىتوان كفت كه 


\begin{tabular}{|c|c|c|c|c|c|c|c|}
\hline \multicolumn{2}{|c|}{ شاخص هم خطى } & \multicolumn{2}{|c|}{ معنادارى ضرايب } & \multicolumn{3}{|c|}{ ضرايب ركرسيون } & \multirow[b]{2}{*}{ متغير بيشبين } \\
\hline Vif & تحمل & معنادارى سطح & مقدار t & استانداردم & خطاى انحراف & غير استاندارد b & \\
\hline & &.$/ \cdots$ & $9 / .9$ & & $\mathrm{~V} / \mathrm{Al}$ & $F V / \Delta \Lambda$ & مقدار ثابت C \\
\hline ( & $\cdot / F F A$ &.$/ \cdot k r$ & $-r / \cdot r \Delta$ & $-\cdot / 1 \wedge 9$ & $\cdot|| r \mid$ & $-\cdot / Y F V$ & اطلاعاتى \\
\hline I/YAD & $\cdot / \mathrm{W} A$ & - /FAY & $-\cdot / V Q r$ & $-\cdot / \cdot \Delta r$ & $\cdot / \mid F A$ &.$- / 111$ & هنجارى \\
\hline $1 / N \mu F$ & $\cdot / \Delta V V$ &.$/ \cdot 1$ & $r / 9.1$ & •/YIY &.$/ 111$ &.$/ Y 9$. & سردر \\
\hline $1 / \Delta \wedge q$ & .1949 & $\cdot / \cdot \mathrm{YA}$ & $-Y / Y Y I$ & $-\cdot / I V F$ & $\cdot / l \Delta r$ & $-\cdot / \mu r V$ & تعهد \\
\hline
\end{tabular}

حسينى ثابت (Y) (Y)، ساويسى و آى سان (Y) (Y) و سيز (Y.|F) مشابه و همسو است. همجنين اين فرضيه با نتايج تحقيقات خانجانى و اكبرى (| (|) كه در تحقيق خود نشان دادند بين تجربه جويى با اعتياد به اينترنت رابطه مثبت و معنىدارى وجود دارد، همسو هست. يافته هاى سلطانى و همكاران (I (IN9) هيجان خواهى بالا از طريق رفتار بى بندبارانه (سهل انكارنه) كه شامل فعاليتهاى خطرناكك، شيوه غير متعارف زندكى و عدم يذيرش يكنواختى هست، بر تجارب جديد و متنوع تمركز مى كنند. نتايج تحقيق مذكور نشان داد كه هيجان خواهى اثر مستقيم بر اعتياد به اينترنت دارد. و نيز رفتارهاى خطر جويانه با اعتياد به اينترنت ارتباط دارند؛ زيرا كسانى كه هيجان جو و ريسك يذ ير ترند در مقايسه با كسانى كه هيجان جويى كمترى دارند، محيط اينترنت و شيوه ارتباطى را مهيجتر مى يابند و تمايل به كشف ناشناختههاى بيشترى دارند.

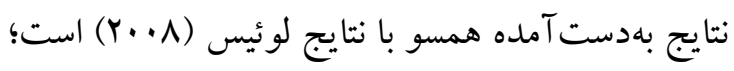
مبنى بر اينكه بين هيجان خواهى و اعتياد به اينترنت ارتباط معنىدارى وجود دارد و اين افراد در زمانهايى، از اينترنت براى تفريح، سركرمى، رفع خستگى و
با توجه به اطلاعات جدول فوق سبكهاى هويت اطلاعاتى و تعهد بهصورت منفى و معنادار بر اعتياد به

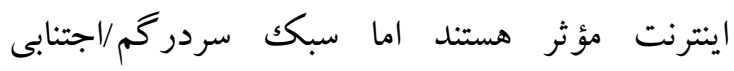
بهورت مثبت و معنادار بر اعتيارى بر اعتياد به اينترنت ندارد. با توجه به مقادير بتاى استاندارد سبك هويت سردركم/اجتنابى (Y/Y/Y / در بيشبينى اعتياد به اينترنت دارد؛ و سبكك اطلاعاتى ( $)$ ( $\beta=-\cdot / / \Lambda 9)$ بيشترين تأثير رابر اعتياد به اينترنت دارند. در آخرين ستون جدول V مقادير شاخص هاى تحمل و ارائهشداند. مقادير اين دو شاخص در مدل VIF ركرسيون فرضيه دوم بثزوهش به ترتيب بيشتر از / • و كمتر از • ا هستند و اين مقادير نشاندهنده عدم وجود هم خطى جِند گانه در متغير ها هستند.

بحث و نتيجه تيرى نتايج حاصل از آزمون فرضيه نخست يزوهش نشان داد كه سه مؤلفه هيجان خواهى يعنى ماجراجويى، تجربه يذيرى و ملال يذيرى توانايى بيشبينى ميزان اعتياد به اينترنت را دارند. اين يافته با نتايج تحقيقات حاج خدادادى، محمد نظرى و منطقى (سوسا) فتحى، سهرابى و سعيديان (YqM)، مظاهرى نجات فرد و 
نتايج حاصل از فرضيه دوم يثزوهش نشان داد كه در مجموع مىتوان بر اساس سبك هويت اطلاعاتى،

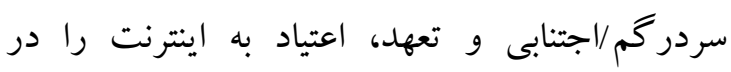

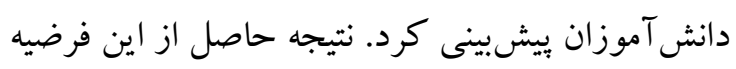
با نتايج تحقيقات قبلى همجون رحمتى و كرامتى

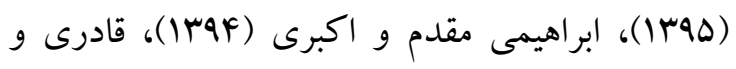

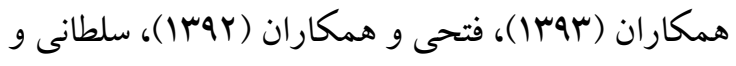

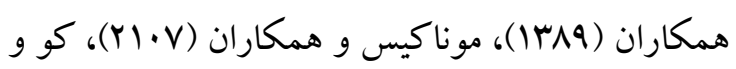

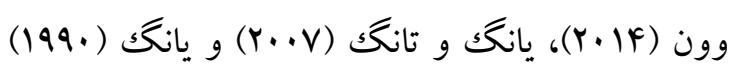

$$
\text { در يكك راستاو جهت قرار دارد. }
$$

براى تبيين اين قسمت از يافته فرضيه دوم بزوهش مبنى بر بيشبينى اعتياد به اينترنت از طريق سبك هويت

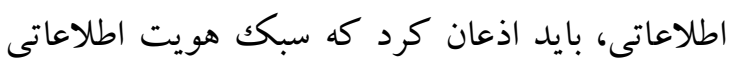

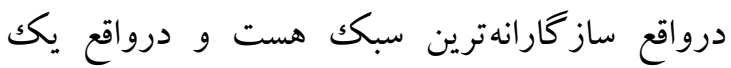
استراتزى حل مسئله و يا مكانيسم كنار آمدن براى اداره موقعيت هاى روزانه است. يكك اكتشاف فعال و يا تعهد منعطف، نياز براى شناخت و سطح بالايى از خوديندارى است. افراد داراى اين سبك هويت، در اداره موقعيتهاى روزانه از يكك مكانيسم سنجيده و منطقى بهرهمند هستند و بنابراين از اينترنت به شكل حسابشده و در مسير اهداف مشخصى استفاده مى كنند. در تبيين عدم بيشبينى اعتياد به اينترنت از روى سبك

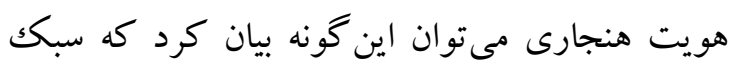

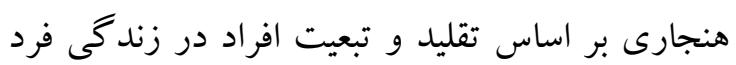

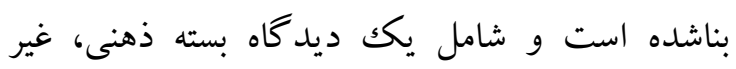
منعطف و يكك خوديندارى ثابت و سركوب كننده اكتشاف است. اين افراد تمايل به درخواست كمكك و

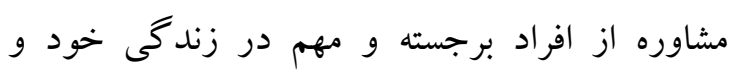
حركت بر روى خط استانداردها دارند و آنها از برخورد با اطلاعاتى كه تعارض با خوديندارىشان دارد، اجتناب مى كنند و تا حد امكان در مقابل تغييرات
رسيدن به شور و هيجان استفاده مى كنند. همجنين نتيجه بهدست آمده از فرضيه نخست وبزوهش با نتايج

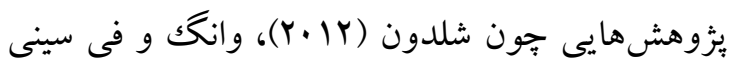

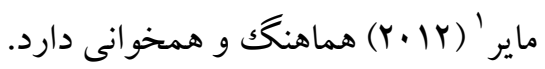
در تبيين اين فرضيه مىتوان جنين اظهارنظر كرد كه افراد هيجان خواه نياز به داشتن تجربههاى متنوع و جديد دارند، تنوعطلبى و جستوجوى تجربههاى جذاب و هيجانانگيز در اين افراد مشاهده مىشود، از

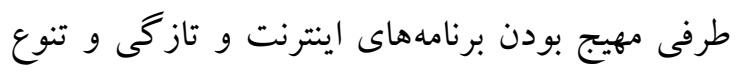
آنها مى تواند عامل جذب افراد به اينترنت باشد. درواقع اينترنت با ويز گیىهاى منحصربهفردى كه دارد

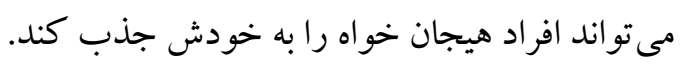
نظريات بسيارى در تبيين اعتياد اينترنتى مطرحشده است. از ديدكاه رفتارى - شناختى نشانهاى اختلال اعتياد اينترنتى شامل افكار وسواسى درباره اينترنت، كنترل تكانه ضعيف، ناتوانى در متوقف كردن استفاده از اينترنت و مهمتر از همه، اين باور است كه اينترنت تنها دوست فرد است. بر اساس رويكرد رفتارگرا پاداشهاى دريافتى از اينترنت كه مىتواند شامل دوستىهاى مجازى و تشكيل اجتماعات مجازى توسط فرد كاربر باشد، منجر به باز گشت دوباره به اين محيط مىشود و انجام اين عمل را در فرد تقويت مىنمايد (ميرزائيان، باعزت و خاكيور، . وسما). در رويكرد استفاده و خشنودى نيز يكى از نيازهايى كه موجب مىشود مخاطبان به سمت رسانه بروند، نياز اجتماعى (كفتگ و تعامل با ديخران) است. معتادان اينترنى نيز در بى يافتن روابطى فراتر از روابط محدود

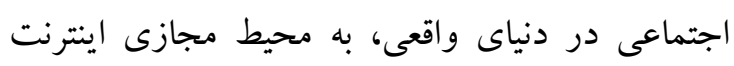
وارد شده و در يى برقرارى ارتباطاتى فارغ از

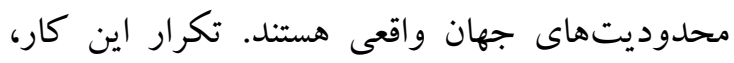
براى آنها مسرّت بخش و اعتياد آوراست.

\footnotetext{
1 - Wang \& Fesenmaier
} 


\section{References}

Berzonsky, M. D. \& Adams, G. R. (1999). Revaluating the identity status paradigm: still useful after 35 years. developmental Review, $19,557-590$.

Berzonsky, M. D. (1989). Identity style: Conceptualization and measurement. Journal of Adolescent Research, 4, 267-281.

Berzonsky, M. D. (2004). Identity style, parental authority, and identity commitment. Journal of Youth and Adolescence, 33(3), 213-220.

Ebrahimi Moghadam, H., \& Akbari, H. (2015). The relationship between identity styles and Intemet addiction among students in science and industry. First International Conference on the Intemational Psychology of Iran. Tehran, Center for Development Conferences, http://www.civilica.com/Paper-PSYI01-

PSYI01_182.html. [In Persian]

Farshbaf, S. (2010). Intemet Addiction: Causes and Motivation, Research and Study on virtual space, Hamshahri Newspaper, 2010/08/28, Content: 3092. [In Persian]

Fathi, M., Sohrabi, F., \& Saidian, M.(2013). Comparison of the characteristics and identity style of Internet addicts and non-addicts students. J Res Behav Sci, 11(2), 90-99. [In Persian]

Gaderi, E., Nabizadeh Chineh, G.h, \& Esmaeili Kouraneh, A. (2014). Identity styles, loneliness and fear of intimacy in people who are addicted to the Internet and normal people. Quarterly national studies, 15(4), 117-136. [In Persian]

Ghaderi Rammazil, M.; Mehdizadeh Zare Anari, A.; Dehghan, H.; \&Najafi, V. (2015). Relationship between parenting styles, identity styles and students' intemet addiction in

Ghazanfari, A. (2009). Validation and standardization of identity style questionnaire (ISI-6G). Educational and Psychological Studies of Ferdowsi University of Mashhad, 17, 81-96. [In Persian]

Haj Khodadadi, D., Nazari, A. M., \& Mantegi, M. (2014). Relationship of Family Performance, Excitement and Aggression with Addiction to

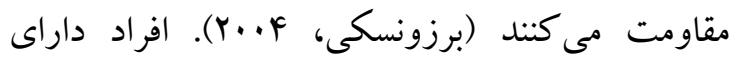
سبك هويت هنجارى، به اين دليل كه هويت آنها داراى يك ساختار زود شكل گرفته است، از روبهرو شدن با موقعيتهاى جالشى همجون اينترنت يرهيز مى كنند. بخشى از يافته فرضيه دوم بيانگر قدرت بيشبينى

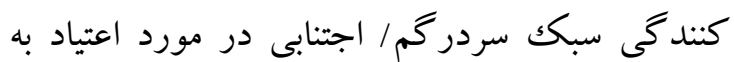
اينترنت بود. براى تبيين اين فرضيه مىتوان به اين مطلب

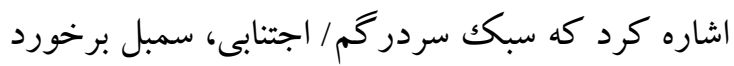
طفرهآميز و مسامحه در مشكلات است. يكك استراتزى متمركز بر هيجان كه با سطوح بِياينى از تعهل و و

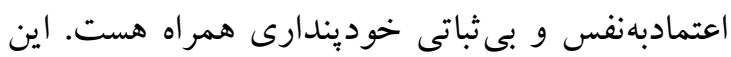
افراد اغلب توجه كمى به آينده و با نتايج طولانىمدات انتخابهاى خود دارند. شايد بتوان كفت كه آنها درگير يكك اكتشاف هستند اما اكتشاف سازمان نايافته و تصادفى است. نتيجه بهدست آمده را مىتوان در جهارجوب نظريه برزونسكى (F) (Y. (Y) به اين شكل تبيين كرد كه اين افراد به دليل عدم اعتمادبهنفس و خود برد بردي ينداره بايين و نيز عدم مهارت لازم جهت ايجاد ارتباط

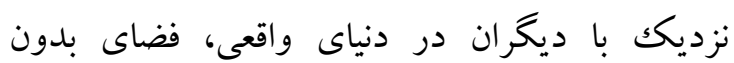
بازخورد منفى همجيون اينترنت را به دنياى واقعى ترجيح دهند و از خمنامى در آن لذت بيرند. درنهايت بر اساس نتايج حاصل از بُزوهش كه بهور كلى نشان داد بين هيجان خواهى و سبككهاى هويت با اعتياد به اينترنت رابطه معنادار وجود دارد،

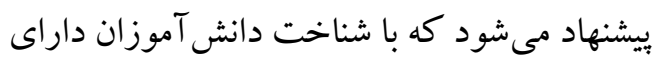

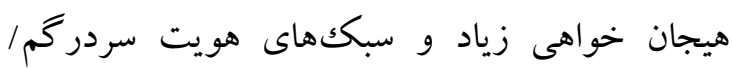

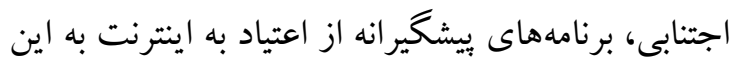

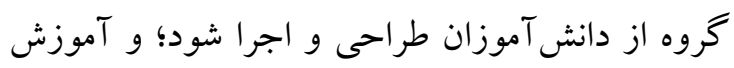
نحوه استفاده صحيح از اينترنت در مدارس از طريق

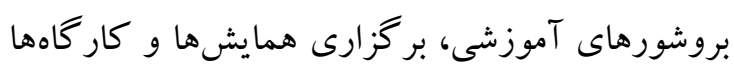
صورت گيرد. 
Imtiaz, S., \& Naqvi, I. (2012). Parental attachment and identity styles among adolescents: Moderating role of gender. Pakistan Joumal of Psychological Research, 27(2), 241.

Javanmard, S., Poorabadi, P., \& Akrami, N. (2013). Predicting the role of Biological Vulnerabilities on Intemet Addiction: BrainBehavioral Systems and Gender. $J$ Mazandaran Univ Med Sci, 23 (102), 4051. [InPersian]

Khanjani, Z. \& Akbari, S. (2011).The Relationship between Teenagers' Personality Traits with Their Intemet Dependence. New Findings in Psychology, 6(19), 113-127. [In Persian]

Kim, E. J.; NamKoong, K.; Ku, T.; \& Kim, S. J. (2012). The relationship between online game addiction and aggression, self-control and nareissistic personality traite. European psychiatry, 23, 212-218.

King, D.; Delfabbro, P. H.; \& Griffiths, M. (2010). Video game structural characteristics: A new psychological taxonomy. International Journal of Mental Health and Addiction, 7, 90-106.

Koo, H. J., \& Kwon, J. H. (2014). Risk and protective factors of Intemet addiction: a meta-analysis of empirical studies in Korea. Yonsei medical journal,55(6), 1691-1711.

Kuss, D. J., Griffiths, M. D., \& Binder, J. F. (2013). Intemet addiction in students: Prevalence and risk factors. Computers in Human Behavior, 29(3), 959-966.

Kuss, D. J.; Shorter, G. W.; van Rooij, A. J.; van de Mheen, D.; \& Griffiths, M. D. (2014). The Intemet addiction components model and personality: Establishing construct validity via a nomological network. Computers in Human Behavior, 39, 312-321. doi: 10.1016/j.chb.2014.07.031

Lehenbauer-Baum, M; \& Fohringer, M. (2015). Towards classification csiteria for internet gaming disorder Debunking differences between addiction and high engagement in a German sample of World of Warcraft players. computer in Human Behavior, 45, 345-351

Louis, L. (2008). Leisure boredom sensation seeking, self-esteem, addiction symptoms andpatterns of mobilePhone use. In Korini, S. Utz, M. Tanis, \& S. Barnes. (Eds), Mediated personal communication (pp359-381). NewYork:
Video Games in Students. Quarterly Journal of Information

Routledge. Advances in psychiatric Treatment; 13: 24-30.Advances in psychiatric Treatment; 13: 24-30.

Mazaheri Nejadfard, G., \& Hosseinsabet, F. (2017). Predicting Intemet Addiction Based on Sensation Seeking: Mediation Effect of Attachment Styles. Journal of Practice in Clinical Psychology, 5(3), 195-202.

Mirzaeean, B., Bazzat, F., \& Khapoor, N. (2011). Intemet addiction among students and their impact on mental health. Quarterly Journal of Information and Communication Technology in Educational Sciences, 2 (1), 141-160. [In Persian]

Monacis, L., de Palo, V., Griffiths, M. D., \& Sinatra, M. (2017). Exploring individual differences in online addictions: The role of identity and attachment. International joumal of mental health and addiction, 15(4),853-868.

Murali, V.; \& George, S. (2007). An overview of intemet addiction. Advances in Psychiatric Treatment, 13, 24-30.

Pallant, J. (2010). SPSS survival manual: A step by step guide to data analysis using SPSS. 4th Edition, Akbar Rezaei trans, Tabriz: Fonuzesh. [n Persian]

Rahmati, S., \& Keramati, H. (2016). The Relationship between the Intemet Addiction and Students' Social Self-Efficacy, Identity Styles and Gender Differences. J Health Syst Res, 12(1), 6-21. [In Persian]

Roberti, W. J. (2004). A review of behavioral and biological comrelates of sensation seeking. Juornal of Research in personality, 38, 256279.

Salmani, B., Hasani, J., \& Arianna Kia, E. (2014). Evaluating the Role of Personality Traits (Consciousness, Agreeableness and Sensation Seeking) in Risky Behaviors. Advances in Cognitive Science. 16(1), 1-10. [In Persian]

Savc1, M., \& Aysan, F. (2016). The role of attachment styles, peer relations, and affections in predicting Internet addiction. Addicta: The Turkish Journal On Addictions,3(3), 416-432.

Sheldon, P. (2012). Profiling the non -users; Examination of life-position indicators, sensation seeking shyness, and loneliness among users and non-users of social network 
sits. Computer in Human behavior, 28, 19601965.

Shirinkam, S. S., Shahsavarani, A. M., Toroghi, L. M., Mahmoodabadi, M., Mohammadi, A., \& Sattari, K. (2016). Internet Addiction Antecendents: Self control as a predictor.Journal international of Medical Research \& Health Sciences,5(5), 143-15.

Siyez, D. M. (2014). Gender and Sensation Seeking as Predictor Variables of Problematic Internet Use by High School Students. Addicta-The Turkish Journal OnAddictions, 1(1), 78-97.

Soltani, M., Fooladvand, K.h., \& Fathi-Ashtiani, A. (2010). Relationship between identity and sensation-seeking with intemet addiction. Journal of Behavioral Sciences, 4(3), 191-197. [In Persian]

Wang, Y. Y.; \& Fesenmaier, D. (2012). Defining the virtual tourist community: implications for tourism marketing. Tourism Management, 23 (4), 401-417
Widyanto, L.; \& Mc Murran, M. (2004). The psychometric propertis of the intemet addiction test. CyberpsychoiBehavior, 7(4), 443-50.

Yang, S.; \& Tung, C. (2007). Comparison of Intemet addicts and non-addicts in Taiwanese high school. Computr Human Behav, 23, 79-96.

Young, Kimberly S. (2004). Intemet Addiction A New Clinical Phenomenon and Its Consequences. American behavioral scientist, 48(4), 402-415.

Young, T. J. (1990). Sensation seeking and Self reported criminality among student-athletes. Perceptual and Motor skilled, 10, 959-962.

Zolfaghari Zafarani, R. \& Kalantari, M. (2016). The Relationship between Excitement and General Health Among Male and Female Students of Islamic Azad University, Roodehen Branch. Social research. 8 (31), 105-118. [InPersian]. 